\title{
Detection of Human Metapneumovirus infection in children under 18 years old hospitalized in Lima-Peru
}

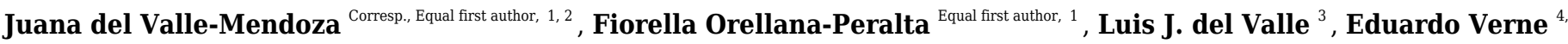 \\ ${ }_{5}$, Claudia Ugarte ${ }^{4,5}$, Claudia Weilg ${ }^{1}$, Wilmer Silva-Caso ${ }^{1,2}{ }$, Jorge Valverde-Ezeta ${ }^{1}$, Hugo Carrillo-Ng ${ }^{2,4}$, Isaac \\ Peña-Tuesta ${ }^{1}$, Carlos Palomares-Reyes ${ }^{1}$, Angela Cornejo-Tapia ${ }^{1}$, Miguel Angel Aguilar-Luis ${ }^{\text {Corresp. } 1,2}$ \\ ${ }^{1}$ School of Medicine, Research and Innovation Centre of the Faculty of Health Sciences., Universidad Peruana de Ciencias Aplicadas, Lima, Peru \\ 2 Laboratorio de Biologia Molecular. Instituto de Investigación Nutricional (IIN), Lima, Peru \\ 3 Barcelona Research Center for Multiscale Science and Engineering, Departament d'Enginyeria Química, EEBE, Universitat Politecnica de Catalunya \\ (UPC). Barcelona Tech, Barcelona, Spain \\ 4 Facultad de Medicina, Universidad Peruana Cayetano Heredia, Lima, Peru \\ 5 Servicio de Pediatria. Hospital Nacional Cayetano Heredia, Lima, Peru \\ Corresponding Authors: Juana del Valle-Mendoza, Miguel Angel Aguilar-Luis \\ Email address: joana.del.valle@gmail.com, miguel.aguilar@upc.pe
}

Background: Human Metapneumovirus (hMPV) is a negative single-stranded RNA virus. Infection by hMPV mainly affects the pediatric population and can cause upper or lower respiratory tract pathologies which can develop life threating complications. This study was carried out between 2009 and 2010 in a high complexity national hospital in Lima, Peru. The time frame corresponds to the pandemic of influenza A H1N1. Methods: A prospective study was performed between September 2009 and September 2010. Patients with a clinical diagnosis suggestive of an acute respiratory infection were included. RT-PCR was utilized to attain the amplification and identification of the hMPV.Results: A total of 539 samples were analyzed from patients with a clinical context suggestive of an acute respiratory tract infection. Of these samples 73 (13.54\%) were positive for hMPV. Out of the positive cases, $63 \%$ were under one year old, and increased to nearly $80 \%$ when considering children younger than two years old. Cough was the most frequent symptom presented by our population with a number of 62 cases $(84.93 \%)$. Viral seasonality was also established, noting its predominance during the months of summer in the southern hemisphere.The infection by hMPV has an important prevalence in Peru. It mainly affects children under one year old and should be considered an important differential diagnosis in a patient with an acute respiratory infection. 
4 Juana del Valle-Mendoza ${ }^{1,2 * \dagger}+$ Fiorella Orellana-Peralta ${ }^{1} \uparrow$; Luis J. del Valle ${ }^{3}$; Eduardo Verne ${ }^{4}$,

5 Claudia Ugarte ${ }^{4}$; Claudia Weilg${ }^{1}$; Wilmer Silva-Caso ${ }^{1,2,}$; Jorge Valverde-Ezeta ${ }^{1}$; Hugo Carrillo6 Ng ${ }^{2,5}$; Isaac Peña-Tuesta ${ }^{1}$; Carlos Palomares-Reyes ${ }^{1}$; Angela Cornejo-Tapia1 ${ }^{1}$ Miguel Angel $7 \quad$ Aguilar-Luis $1,2 *$

8

$9{ }^{1}$ School of Medicine, Research and Innovation Centre of the Faculty of Health Sciences.

\section{Detection of Human Metapneumovirus infection in children under 18 years old}

\author{
hospitalized In Lima- Peru
}

Universidad Peruana de Ciencias Aplicadas. Lima, Perú.

${ }^{2}$ Laboratorio de Biología Molecular. Instituto de Investigación Nutricional (IIN). Lima-Perú.

${ }^{3}$ Barcelona Research Center for Multiscale Science and Engineering, Departament d'Enginyeria Química, EEBE, Universidad Politecnica de Catalunya (UPC), Barcelona Tech, Barcelona, Spain.

${ }^{4}$ Servicio de Pediatria. Hospital Nacional Cayetano Heredia. Lima, Peru.

${ }^{5}$ Facultad de Medicina. Universidad Peruana Cayetano Heredia. Lima, Peru.

$\uparrow$ These authors contributed equally to this article.

* Corresponding author

1 Juana del Valle Mendoza, e-mail: juana.delvalle@upc.pe

22 Miguel Angel Aguilar-Luis, email: miguel.aguilar@upc.pe

3 Universidad Peruana de Ciencias Aplicadas. Av. San Marcos cuadra 2, Chorrillos, Lima, Peru

4 Phone +511988040532 , Fax. +5113496023 


\section{ABSTRACT}

27

28 Background: Human Metapneumovirus (hMPV) is a negative single-stranded RNA virus.

29 Infection by hMPV mainly affects the pediatric population and can cause upper or lower respiratory tract pathologies which can develop life threating complications. This study was carried out between 2009 and 2010 in a high complexity national hospital in Lima, Peru. The time frame corresponds to the pandemic of influenza A H1N1.

Methods: A prospective study was performed between September 2009 and September 2010.

Patients with a clinical diagnosis suggestive of an acute respiratory infection were included. RTPCR was utilized to attain the amplification and identification of the hMPV.

Results: A total of 539 samples were analyzed from patients with a clinical context suggestive of 37 an acute respiratory tract infection. Of these samples $73(13.54 \%)$ were positive for hMPV. Out 38 of the positive cases, $63 \%$ were under one year old, and increased to nearly $80 \%$ when considering children younger than two years old. Cough was the most frequent symptom presented by our population with a number of 62 cases $(84.93 \%)$. Viral seasonality was also established, noting its predominance during the months of summer in the southern hemisphere. year old and should be considered an important differential diagnosis in a patient with an acute 44 respiratory infection. 


\section{INTRODUCTION}

50

51 The Human Metapneumovirus (hMPV) is a negative single-stranded RNA virus. It belongs to

52 the family Pneumoviridae, which includes the genus Metapneumovirus and Orthopneumovirus,

53 whose main representatives are the Human Metapneumovirus (hMPV) and the Respiratory

54 Syncytial Virus, respectively [1]. The hMPV was initially isolated and described in the

55 Netherlands during the year 2001; however, it is presumed that hPMV is responsible for

56 respiratory infections dating back to approximately six decades [1-5]. According to the

57 phylogenetic analysis, within the most frequent isolated genotypes, two subgroups of hPMV

58 have been identified: A and B, which include subtypes A1, A2, B1 and B2 [5, 6].

59 Infection due to hMPV mainly affects the pediatric population and can cause diverse pathologies

60 of the upper or lower respiratory tract, which include rhinopharyngitis, laryngitis, croup,

61 pneumonia, bronchiolitis or asthma exacerbations [7,8]. Furthermore, It also affects the adult

62 population, predominantly elderly and immunosuppressed patients [8]. Although the clinical

63 context most frequently consists of an asymptomatic period that lasts approximately seven days

64 post exposure, followed by a week of symptoms of an upper respiratory tract infection with

65 gradual resolution, the clinical course can progress toward the lower respiratory tract resulting in

66 lung parenchymal involvement and cause further complications [9-13]. It is estimated that

67 infections caused by hMPV are accountable for approximately 20,000 hospitalizations per year

68 in children under five years old in the United States [14]. However, the available information

69 regarding its epidemiology is limited due to a deficient suspicion and its clinical similarity with

70 other respiratory viruses such as the Influenza virus and the Respiratory Syncytial Virus. It has

71 been described and established in western countries, that the prevalence of the Human 
72 Metapneumovirus increases during the late winter months and the beginning of the spring;

73 however, it has also been reported during late spring and summer months in cities such as Hong

74 Kong [1,7,15-17]. Currently, due to the limited availability of molecular methods for the precise

75 diagnosis of viral pathologies such as those caused by hMPV, leads to poor epidemiological data

76 in Latin American countries such as Peru. The aim of this study is to identify the Human

77 Metapneumovirus responsible for acute respiratory infections in children from September 2009

78 to September 2010 in Lima, Peru.

79

80

MATERIALS AND METHODS

81

82 Patients

83 We performed a prospective study between September 2009 and September 2010 in a high

84 complexity national hospital in Lima, Peru. The time frame corresponds to the pandemic of 85 influenza A H1N1. In this study we included all the patients with clinical diagnosis of acute respiratory infections (ARI). We use the operative definition of ARI, according to the sanitary

87 directives of the Ministry of Health of Peru, as any infection that involves one or more parts of

88 the respiratory system, with a duration of less than 14 days and with the presence of one or more

89 clinical signs: cough, rhinorrhea, nasal obstruction, odynophagia, dysphonia, otalgia, noisy

90 breathing, respiratory distress, which may or may not be accompanied by fever. The

91 epidemiological and clinical data were: age, clinical symptoms (fever: defined as temperature

92 higher than $38^{\circ} \mathrm{C}$, rhinorrhea, cough, respiratory difficulty, sore throat, wheezing, discomfort,

93 pharyngeal congestion, expectoration, vomiting, diarrhea, others.). 


\section{Ethics statement}

96 Samples were collected following a written informed consent signed by all the parents or

97 respective caregiver because the patients were under 18 years of age. This study has been 98 approved by two independent Ethics Committees from Hospital Nacional Cayetano Heredia 99 (Ethical Application $\mathrm{N}^{\mathrm{o}}$ 021-09) and Instituto de Investigación Nutricional (Ethical Application $100 \quad N^{0} 279-2009$ / CEI-IIN) in Lima, Peru.

101

102 Samples

103 To obtain the samples we used two different swabs. A first swab was inserted into both nostrils 104 parallel to the palate to obtain the nasopharyngeal samples (Mini-Tip Culture Direct, Becton105 Dickinson Microbiology System, MD 21152, USA). The second swab was inserted into the 106 posterior pharyngeal and tonsillar areas (Viral Culturette, Becton-Dickinson Microbiology 107 Systems, MD, USA). A tube containing viral transport medium (minimal essential medium with $1082 \%$ fetal bovine serum, amphotericin B $20 \mu \mathrm{g} / \mathrm{ml}$, neomycin $40 \mu \mathrm{g} / \mathrm{ml}$,) was used to store both 109 swabs. Two aliquots of each fresh specimen were stored at $-20{ }^{\circ} \mathrm{C}$ to be later analyzed for 110 hMPV.

\section{RNA extraction}

113 The viral genetic material was extracted used the High Pure RNA Isolation Kit (Roche Applied

114 Science, Mannheim, Germany) to perform the RNA extraction from $200 \mu \mathrm{L}$ of the samples, 115 according to the manufacturer's instructions. Viral RNA obtained after the extraction was eluted 116 in $100 \mu 1$ of nuclease-free water. 
118 Reverse Transcriptase Polymerase chain reaction (RT-PCR) for the analysis of Human

119 Metapneumovirus (hMPV).

120 A one-step RT-PCR was performed using Real Time ready RNA Virus Master (Roche 121 Diagnostic, Deutschland-Mannheim, Germany) and $250 \mathrm{nM}$ specific primers for hMPV in a final 122 volume of $20 \mu \mathrm{L}$. The primers were described by Van den Hoogen et al., 2003 [1], amplifying a 123 conserved fragment of $170 \mathrm{nt}$ in the polymerase chain. Five microliters of the extracted RNA 124 was combined with $15 \mu \mathrm{l}$ of the master mix and the reverse transcription step was performed $12545^{\circ} \mathrm{C}$ for 45 minutes and the amplification consisted of an initial incubation at $95^{\circ} \mathrm{C}$ for 2 min, 126 followed by 45 cycles of $95^{\circ} \mathrm{C}$ for $1 \mathrm{~min} ; 50^{\circ} \mathrm{C}$ for $1 \mathrm{~min}$, and $72^{\circ} \mathrm{C}$ for $30 \mathrm{sec}$; with a final 127 extension at $72^{\circ} \mathrm{C}$ for $10 \mathrm{~min}$.

128 Amplified products were recovered from the gel, purified (SpinPrep Gel DNA Kit; San Diego, $129 \mathrm{CA}$ ) and sent for commercial sequencing (Macrogen, Korea).

Statistic analysis

132

133 The data was registered in a database designed in Access and for further analysis they were 134 exported to an Excel file. The tabulated data were shown as percentage frequencies or counts. The graphics were prepared with the OriginPro v8 software, and analyzed with the Minitab v18 136 software.

RESULTS 
140 A total of 539 samples belonging to patients with a clinical context suggestive of an acute

141 respiratory tract infection were analyzed. Of these samples, 73 were positively identified using

142 RT-PCR for hMPV. This finding establishes a prevalence of $13.54 \%$ for hMPV in the population

143 studied. Nonetheless, the probability or risk of associating a clinical course of a symptomatic

144 acute respiratory tract infection to the presence of hMPV was less than $3 \%$ as demonstrated by

145 the calculated OR (Table 1). This result suggests that other etiological agents (p.e. RSV,

146 influenza, etc.) have a greater probability to be present in the setting of an acute respiratory tract

147 infection $[18,19]$.

148 This study also found that $63 \%$ of the positive cases for hMPV identified through PCR

149 corresponded to children under one year of age, and this percentage increased to around $80 \%$

150 when considering children under two years of age. The same distribution was observed in the

151 total cases for acute respiratory tract infections. Thus, in both cases, the age distribution can be

152 adjusted to exponential models (Figure 1a) and where it can clearly be seen that acute respiratory

153 tract infections are more frequent children under two years of age. Additionally, it can be

154 indicated that the sex of children is not a factor associated with the prevalence of hMPV (Figure

155 1b).

156 More than $90 \%$ of children diagnosed with an hMPV respiratory tract infection identified

157 positively by PCR were hospitalized. In these patients, the most common signs and symptoms 158 were cough which was present in $84.93 \%$ cases $(n=62)$, followed by fever with $75.34 \%(n=55)$

159 and rhinorrhea $71.23 \%(\mathrm{n}=52)$. In addition, 51 patients $(69.86 \%)$ presented with dyspnea. This

160 distribution of signs and symptoms was similar for both the population of children with a

161 negative PCR for hMPV, and for all the children clinically diagnosed with an acute respiratory

162 tract infection (Figure 2a). It is important to note that of the total of cases studied $(n=539)$, 
163 mortality was observed in three patients who happened to be negative via PCR for hMPV 164 infection.

165 Figure $2 b$, shows the correlation analysis of the signs and symptoms identified in the group of 166 positive patients for hMPV identified through PCR and the total of patients with an acute 167 respiratory tract infection. Also, between positive and negative patients for hMPV identified 168 through PCR. Clearly, it is observed that in all these cases there is a high correlation $(\mathrm{r} \sim 1)$. This 169 emphazises that a patient with a respiratory tract infection caused by hMPV, can present a wide 170 range of signs and symptoms which can hardly be discriminated from a clinical diagnosis of an 171 acute respiratory tract infection. Respiratory tract infections caused by hMPV have been 172 described as a seasonal pattern of infectious disease [18, 19]. Figure 3 shows the monthly and 173 seasonal distribution of the acute respiratory tract infections cases and those with a positive PCR 174 for hMPV. The cases of hMPV appear in the month of December $2009(n=10)$, increased during 175 the month of January $2010(n=15)$ and the highest number of positive cases were recorded during 176 the month of March $2010(n=21)$ coinciding with the maximum number of cases diagnosed 177 clinically as an acute respiratory tract infection. Seasonality (in this hemisphere) corresponds to 17842 cases during the months of summer, 21 cases were reported in the fall and spring was the 179 season with the least prevalence of cases $(n=3)$ (Figure 3$)$.

\section{DISCUSSION}

182

183 After its first identification and description in 2001, the Human Metapneumovirus (hMPV) has

184 been detected in patients with respiratory tract infections in Europe, Asia, Oceania, Africa, South 185 America [20, 21]. In Peru, between the years 2002 and 2003, genotype B1 was isolated by RT- 
186 PCR in mainly patients under five years old [22]. Nonetheless, due to the clinical course 187 similarity it shares with other respiratory viruses it presents as an obstacle for healthcare 188 providers at the time of establishing the etiological diagnosis of the disease. Therefore, its 189 incidence, most affected population, most frequent clinical presentation and seasonal distribution 190 are not well determined. In the present study, 73 cases were isolated during the 13 months in 191 which samples from patients with a clinical course similar to an influenza infection were 192 evaluated. Of the sampled analyzed 13,54\% were positive via PCR for hMPV infection, which 193 represents a percentage that merits consideration of hMPV infection as a differential diagnosis in 194 patients with the aforementioned clinical picture. The available information on seroprevalence 195 suggests that the majority of patients have been infected before the age of five [1]. Various 196 studies report a prevalence between $5 \%$ and $15 \%$ in the pediatric population with a clinical 197 course similar to influenza $[7,9,16,23-28]$. It is also known that the majority of cases correspond 198 to children under one year of age and that early age is associated with greater need for 199 hospitalization [14]. The findings in the present study are consistent with the literature reviewed, 200 in which $63.01 \%$ of positive cases correspond to children under 1 year and $84.93 \%$ of cases 201 belong to children under five years old. In relation to the symptoms presented by our study 202 population, $[7,14,23]$ the most frequent symptom was cough, a finding that coincides with our 203 study, in which this symptom was observed with a frequency of $84.93 \%$ in the patients who were 204 positive for hMPV. The second most frequent symptom found in our study was fever $(75.34 \%)$; 205 however, according to different studies it can present with a prevalence ranging from $52 \%$ to $20686 \%$ depending on the series. On the other hand, dyspnea was identified in $69.86 \%$ of the 207 patients, which indicates that the lower respiratory tract is usually compromised. In addition, 208 although the classical theory on viral replication suggests that hMPV infection is limited to the 
209 respiratory tract, cases have been reported of viral encephalitis in children with respiratory tract 210 infections by hMPV, in which the virus has been isolated postmortem from the cerebrospinal 211 fluid (CSF) [29, 30]. Of the total number of samples analyzed, four samples came from patients 212 with a clinical diagnosis of Encephalitis; However, after rigorous analysis, none was positive for 213 hMPV infection. It has been described that Human Metapneumovirus infection can cause 214 exacerbations of obstructive conditions such as Asthma and Chronic Obstructive Pulmonary 215 Disease [31-33]. This is important in the context of respiratory infections caused by viruses such 216 as RSV that cause Bronchiolitis in the pediatric population and it has been associated to the 217 development or susceptibility to suffer from asthma in the future [34]. In addition, the possibility 218 of partial cross-immunity between both viruses is evaluated, since monoclonal antibodies are 219 capable of neutralizing RSV and hMPV $[25,26]$. The diagnosis of an infection caused by hMPV 220 can be made through serology, direct immunofluorescence, viral culture and RT-PCR. Currently, molecular diagnosis by RT-PCR, either conventional or real-time, offers the highest sensitivity 222 than the rest of diagnostic methods previously described $[1,7,9,10,23]$. In the present study, 223 all the samples were analyzed via RT-PCR to establish the diagnosis of hMPV infection. The seasonality of the virus was observed in the majority of studies during the spring season in 225 western countries; however, in the present study, $57.53 \%$ of cases occurred during the summer months, with the month of March exhibiting the highest number of cases $(n=21)$. This finding could be partly explained because more than 80 ARIs were reported during that month, a higher number than any other period during the study. This finding emphasizes the importance of 229 describing the seasonal behavior of hMPV and respiratory viruses that cause similar respiratory 230 clinical courses, so that doctors can use as a tool to make more targeted diagnoses. 
231 A limitation in this study was that we did not evaluate other viral or bacterial etiological agents

232 that could be responsible for coinfections. The clinical characteristics in the presence of 233 coinfection could differ from those with unique infection by hMPV. Another limitation is that 234 the type of sampling in our study supposes a potential selection bias. However, due to our 235 interest in studying the presence of hMPV in patients with ARI, it was the most feasible and 236 efficient sampling selection approach for the context in which it was performed.

237

238 CONCLUSION

239

240 Respiratory tract infections caused by hMPV has an important prevalence in Latin American 241 countries, such as Peru. It mainly affects children under one year old and can cause upper and 242 lower respiratory tract infections. It is important to conduct further studies and to provide 243 sustained epidemiological surveillance that allows the attending physician to have the pertinent 244 information available to suspect an infection by hMPV. Moreover, molecular diagnostic methods 245 such as RT-PCR still require standardization; however, it would be ideal if they were available in 246 reference laboratories from all health care facilities in order to provide a specific etiologic 247 diagnosis with the best sensitivity and specificity available.

\section{ACKNOWLEDGMENTS}

250 We thank to the staff of the Hospital Nacional Cayetano Heredia from Lima, Peru. 251

\section{REFERENCES}


1. van den Hoogen BG, de Jong JC, Groen J, Kuiken T, de Groot R, Fouchier RA,Osterhaus

254

255

256

257

258

259

260

261

262

263

264

265

266

267

268

269

270

271

272

273

274

275

276

AD. A newly discovered human pneumovirus isolated from young children. DOI:

$10.1038 / 89098$

2. Boivin G, Abed Y, Pelletier G, Ruel L, Moisan D, Côté S, Peret TC, Erdman DD,

Anderson LJ. Virological features and clinical manifestations associated with human metapneumovirus: a new paramyxovirus responsible for acute respiratory-tract infections in all age groups. J Infect Dis. 2002 Nov 1;186(9):1330-4. DOI: 10.1086/344319

3. Nissen MD, Siebert DJ, Mackay IM, Sloots TP, Withers SJ. Evidence of human metapneumovirus in Australian children. Med J Aust. 2002 Feb 18;176(4):188.

4. Peret TC, Boivin G, Li Y, Couillard M, Humphrey C, Osterhaus AD, Erdman DD, Anderson LJ. Characterization of human metapneumoviruses isolated from patients in North America. J Infect Dis. 2002 Jun 1;185(11):1660-3. DOI: 10.1086/340518.

\section{Boivin G, Mackay I, Sloots TP, Madhi S, Freymuth F, Wolf D, Shemer-Avni Y,}

Ludewick H, Gray GC, LeBlanc E. Global genetic diversity of human metapneumovirus fusion gene. Emerg Infect Dis 2004; 10:1154. DOI: 10.3201/eid1006.031097.

6. Mackay IM, Bialasiewicz S, Jacob KC, McQueen E, Arden KE, Nissen MD, Sloots TP. Genetic diversity of human metapneumovirus over 4 consecutive years in Australia. J Infect Dis 2006; 193:1630. DOI: 10.1086/504260.

7. Williams JV, Harris PA, Tollefson SJ, Halburnt-Rush LL, Pingsterhaus JM, Edwards KM, Wright PF, Crowe JE Jr. Human metapneumovirus and lower respiratory tract disease in otherwise healthy infants and children. N Engl J Med 2004; 350:443. DOI:10.1056/NEJMoa025472.

8. Boivin G, De Serres G, Hamelin ME, Côté S, Argouin M, Tremblay G, Maranda-Aubut R, Sauvageau C, Ouakki M, Boulianne N, Couture C. An outbreak of severe respiratory tract 
277 infection due to human metapneumovirus in a long-term care facility. Clin Infect Dis. 278 2007;44(9):1152-1158pmid:17407031. DOI: 10.1086/513204

279 9. Boivin G, De Serres G, Côté S, Gilca R, Abed Y, Rochette L, Bergeron MG, Déry P. 280 Human metapneumovirus infections in hospitalized children. Emerg Infect Dis. 2003 281 Jun;9(6):634-40. DOI:10.3201/eid0906.030017

282 10. Falsey AR, Erdman D, Anderson LJ, Walsh EE. Human metapneumovirus infections in 283 young and elderly adults. J Infect Dis 2003; 187:785. DOI:10.1086/367901

284 11. Mullins JA, Erdman DD, Weinberg GA, Edwards K, Hall CB, Walker FJ, Iwane M, 285 Anderson LJ. Human metapneumovirus infection among children hospitalized with acute 286 respiratory illness. Emerg Infect Dis 2004; 10:700. DOI:10.3201/eid1004.030555

287

12. Xepapadaki P, Psarras S, Bossios A, Tsolia M, Gourgiotis D, Liapi-Adamidou G, 288 Constantopoulos AG, Kafetzis D, Papadopoulos NG. Human Metapneumovirus as a causative 289 agent of acute bronchiolitis in infants. J Clin Virol 2004; 30:267. DOI:10.1016/j.jcv.2003.12.012

13. Schlapbach LJ, Agyeman P, Hutter D, Aebi C, Wagner BP, Riedel T. Human 291 metapneumovirus infection as an emerging pathogen causing acute respiratory distress 292 syndrome. J Infect Dis 2011; 203:294. DOI:10.1093/infdis/jiq045

14. Edwards KM, Zhu Y, Griffin MR, Weinberg GA, Hall CB, Szilagyi PG, Staat MA, 294 Iwane M, Prill MM, Williams JV; New Vaccine Surveillance Network. Burden of human 295 metapneumovirus infection in young children. $\mathrm{N}$ Engl $\mathrm{J}$ Med. 2013;368(7):633643pmid:23406028. DOI:10.1056/NEJMoa1204630 9:628. DOI:10.3201/eid0906.030009 
16. Døllner H, Risnes K, Radtke A, Nordbø SA. Outbreak of human metapneumovirus 301 infection in norwegian children. Pediatr Infect Dis J 2004; 23:436.

302 17. Haynes AK, Fowlkes AL, Schneider E, Mutuc JD, Armstrong GL, Gerber SI. Human 303 Metapneumovirus Circulation in the United States, 2008 to 2014. Pediatrics 2016; 137. 304 DOI:10.1542/peds.2015-2927

18. Appak Ö, Duman M, Belet N, Sayiner AA. Viral respiratory infections diagnosed by 306 multiplex polymerase chain reaction in pediatric patients. J Med Virol. 2018 Dec 20. DOI:10.1002/jmv.25379

308

19. Brini Khalifa I, Hannachi N, Guerrero A, Orth-Höller D, Bhiri S, Bougila J, 309 Boughamoura L, Merchaoui SN, Sboui H, Mahdhaoui N, Schiela B, Laer DH, Boukadida J, Stoiber H. Demographic and seasonal characteristics of respiratory pathogens in neonates and 311 infants aged 0 to 12 months in the Central-East region of Tunisia. J Med Virol. 2018 Oct 23. DOI:10.1002/jmv.25347

20. Hamelin ME, Abed Y, Boivin G. Human metapneumovirus: a new player among 314 respiratory viruses. Clin Infect Dis. 2004;38:983-90. DOI:10.1086/382536

315 21. Druce J, Tran T, Kelly H, Kaye M, Chibo D, Kostecki R, Amiri A, Catton M, Birch C. 316 Laboratory diagnosis and surveillance of human respiratory viruses by PCR in Victoria, 317 Australia, 2002-2003. J Med Virol. 2005;75:122-9. DOI:10.1002/jmv.20246

318 22. Gray, G., Capuano, A., Setterquist, S., Sanchez, J., Neville, J., Olson, J., Lebeck, M., 319 McCarthy, T., Abed, Y. and Boivin, G. (2006). Human Metapneumovirus, Peru. Emerging 320 Infectious Diseases, 12(2), pp.347-350. DOI:10.3201/eid1202.051133 
321

322

323

324

325

326

327

328

329

330

331

332

333

334

335

336

337

338

339

340

341

23. Esper F, Martinello RA, Boucher D, Weibel C, Ferguson D, Landry ML, Kahn JS. A 1-

year experience with human metapneumovirus in children aged $<5$ years. J Infect Dis 2004; 189:1388. DOI:10.1086/382482

24. Louie JK, Schnurr DP, Pan CY, Kiang D, Carter C, Tougaw S, Ventura J, Norman A, Belmusto V, Rosenberg J, Trochet G. A summer outbreak of human metapneumovirus infection in a long-term-care facility. J Infect Dis 2007; 196:705. DOI: 10.1086/519846

25. Schuster JE, Cox RG, Hastings AK, Boyd KL, Wadia J, Chen Z, Burton DR, Williamson RA, Williams JV. A broadly neutralizing human monoclonal antibody exhibits in vivo efficacy against both human metapneumovirus and respiratory syncytial virus. J Infect Dis 2015; 211:216. DOI:10.1093/infdis/jiu307

26. Corti D, Bianchi S, Vanzetta F, Minola A, Perez L, Agatic G, Guarino B, Silacci C, Marcandalli J, Marsland BJ, Piralla A, Percivalle E, Sallusto F, Baldanti F, Lanzavecchia A. Cross-neutralization of four paramyxoviruses by a human monoclonal antibody. Nature 2013; 501:439. DOI:10.1038/nature12442

27. Bhattacharyya S, Gesteland PH, Korgenski K, Bjørnstad ON, Adler FR. Cross-immunity between strains explains the dynamical pattern of paramyxoviruses. Proc Natl Acad Sci U S A 2015; 112:13396. DOI:10.1073/pnas.1516698112.

28. Williams JV, Wang CK, Yang CF, Tollefson SJ, House FS, Heck JM, Chu M, Brown JB, Lintao LD, Quinto JD, Chu D, Spaete RR, Edwards KM, Wright PF, Crowe JE Jr. The role of human metapneumovirus in upper respiratory tract infections in children: a 20 -year experience. J Infect Dis 2006; 193:387. DOI:10.1086/499274

Peer] reviewing PDF | (2019:02:34835:1:2:NEW 24 May 2019) 
343 Pneumococcal coinfection with human metapneumovirus. J Infect Dis 2006; 193:1236.

344 DOI:10.1086/503053

345 30. Schildgen O, Glatzel T, Geikowski T, Scheibner B, Matz B, Bindl L, Born M, Viazov S, 346 Wilkesmann A, Knöpfle G, Roggendorf M, Simon A. Human metapneumovirus RNA in 347 encephalitis patient. Emerg Infect Dis 2005; 11:467. DOI:10.3201/eid1103.040676

348 31. Williams JV, Crowe JE Jr, Enriquez R, Minton P, Peebles RS Jr, Hamilton RG, Higgins 349 S, Griffin M, Hartert TV. Human metapneumovirus infection plays an etiologic role in acute 350 asthma exacerbations requiring hospitalization in adults. J Infect Dis 2005; 192:1149. 351 DOI:10.1086/444392

352 32. Vicente D, Montes M, Cilla G, Pérez-Trallero E. Human metapneumovirus and chronic 353 obstructive pulmonary disease. Emerg Infect Dis 2004; 10:1338. DOI:10.3201/eid1007.030633

354 33. Beckham JD, Cadena A, Lin J, Piedra PA, Glezen WP, Greenberg SB, Atmar RL. 355 Respiratory viral infections in patients with chronic, obstructive pulmonary disease. J Infect $356 \quad 2005 ;$ 50:322. DOI:10.1016/j.jinf.2004.07.011

357 34. Openshaw PJ, Dean GS, Culley FJ. Links between respiratory syncytial virus 358 bronchiolitis and childhood asthma: clinical and research approaches. Pediatr Infect Dis J 2003; 359 22:S58. DOI:10.1097/01.inf.0000053887.26571.eb

360

361

362

363 


\section{TABLE Y FIGURES}

366

367 Table 1. Frequency and prevalence of the hMPV infection.

368

369 Figure 1. Distribution of patients by age (a) and sex (b).

370

371 Figure 2. Clinical symptoms. Frequency distribution (a) and correlation analysis (b).

372

373 Figure 3. Monthly distribution of cases. The gray box indicates the months of greatest 374 incidence. Inset, seasonal distribution. 


\section{Table $\mathbf{1}$ (on next page)}

Table 1. Frequency and prevalence of the hMPV infection. 
1

2 Table 1. Frequency and prevalence of the hMPV infection.

3

\begin{tabular}{ccccc}
\hline \multirow{2}{*}{ Cases } & \multicolumn{4}{c}{ PCR } \\
\cline { 2 - 5 } & $\begin{array}{c}\text { Frequency } \\
(\mathbf{N})\end{array}$ & $\begin{array}{c}\text { Prevalence } \\
(\mathbf{\%})[\mathbf{C I} \text { 95\%] }\end{array}$ & Odds [CI 95\%] & Odds ratio [CI 95\%] \\
\hline Positives & 73 & $13.54[10.91-16.69]$ & $0.16[0.11-0.20]$ & $0.03[0.01-0.06]$ \\
Negatives & 466 & $86.46[83.31-89.09]$ & $6.38[5.14-7.92]$ & \\
Total & 539 & 100.00 & & \\
\hline
\end{tabular}

4

5

6

7

8

9

10

11

12

13

14

15

16

17

18

19

20

21

22

23

24

25

26

27

28

29

30

31

32

33 
34

35

36 
Figure 1

Figure 1. Distribution of patients by age (a) and sex (b). 


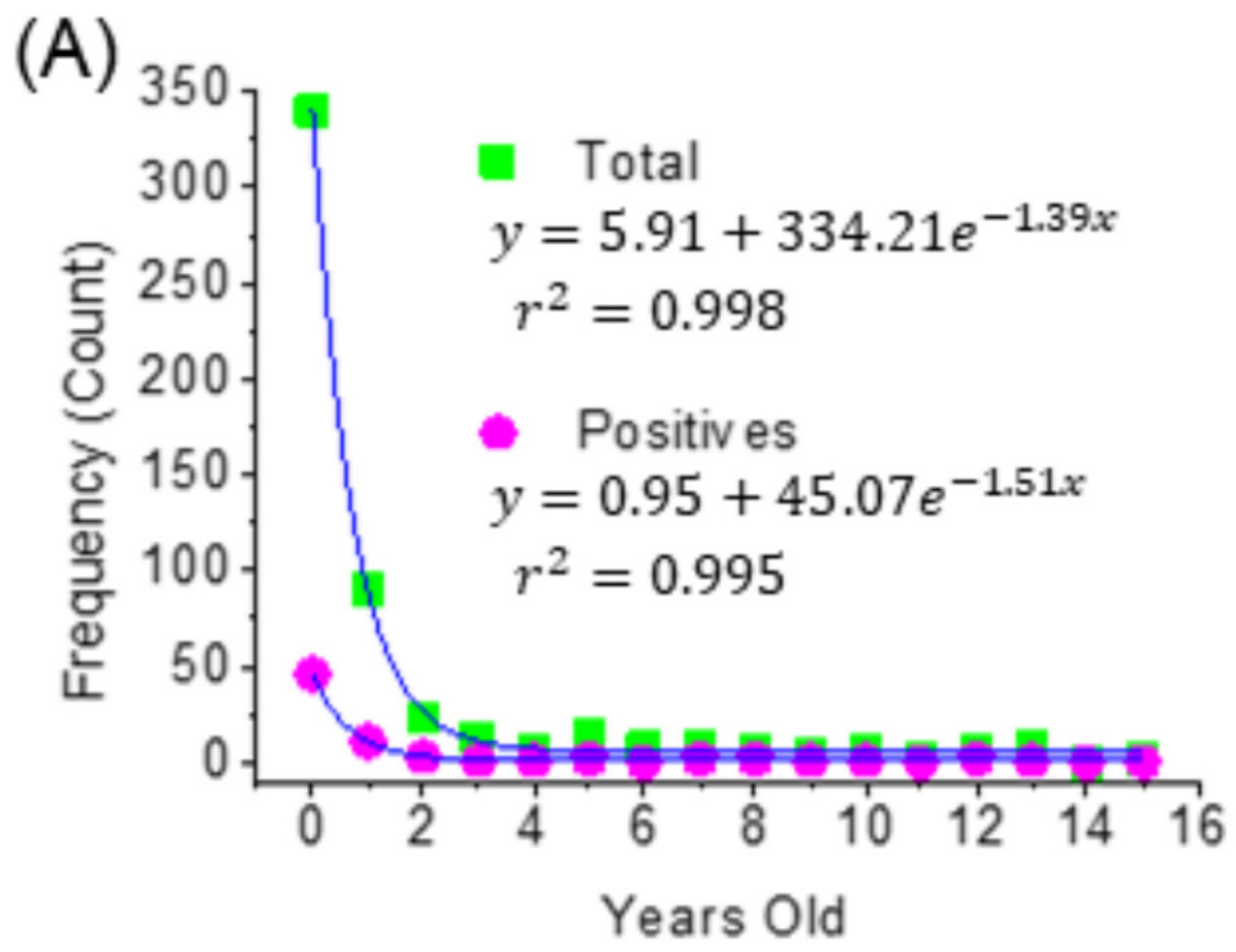

(B)

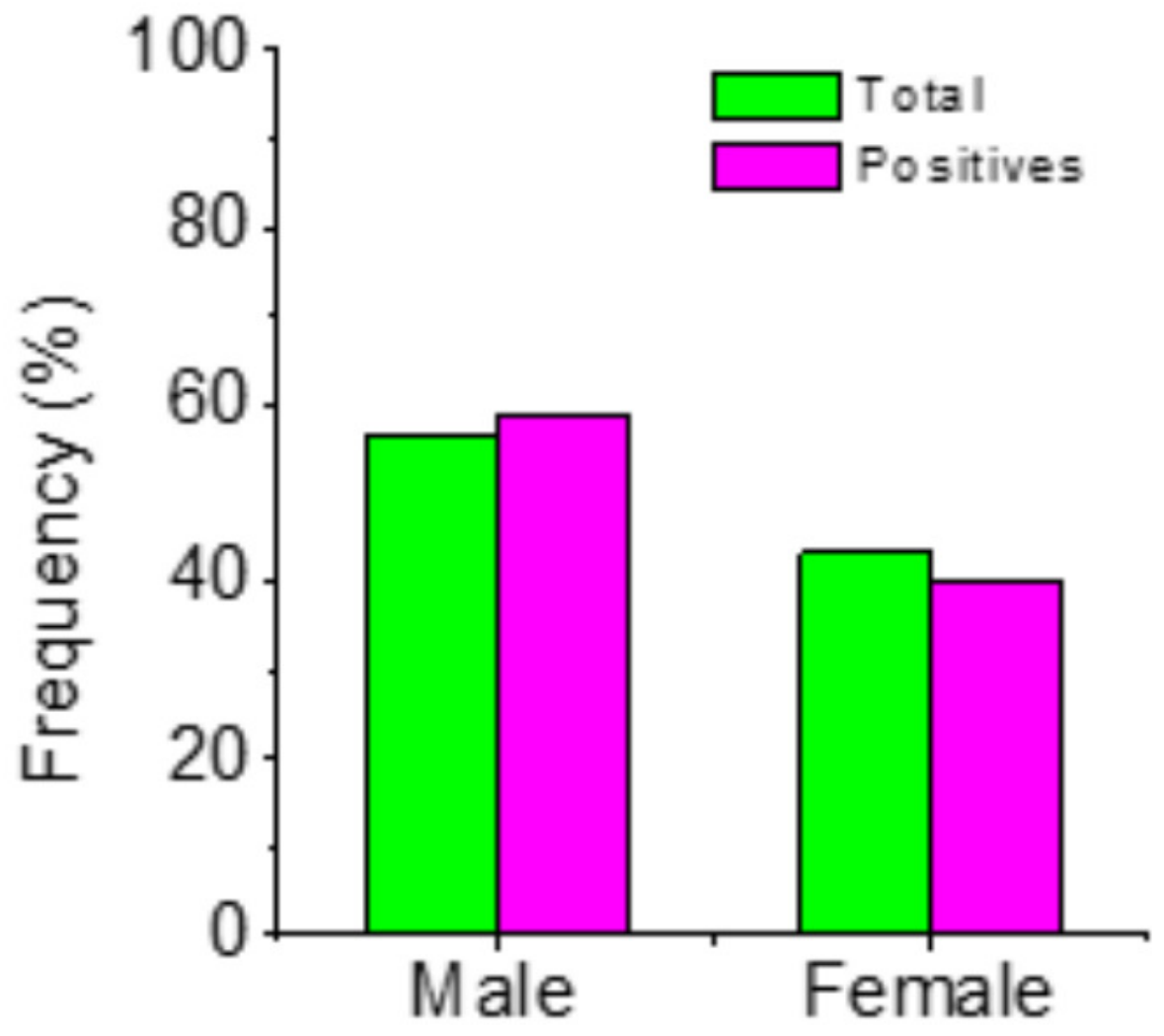


Figure 2

Figure 2. Clinical symptoms. Frequency distribution (a) and correlation analysis (b).
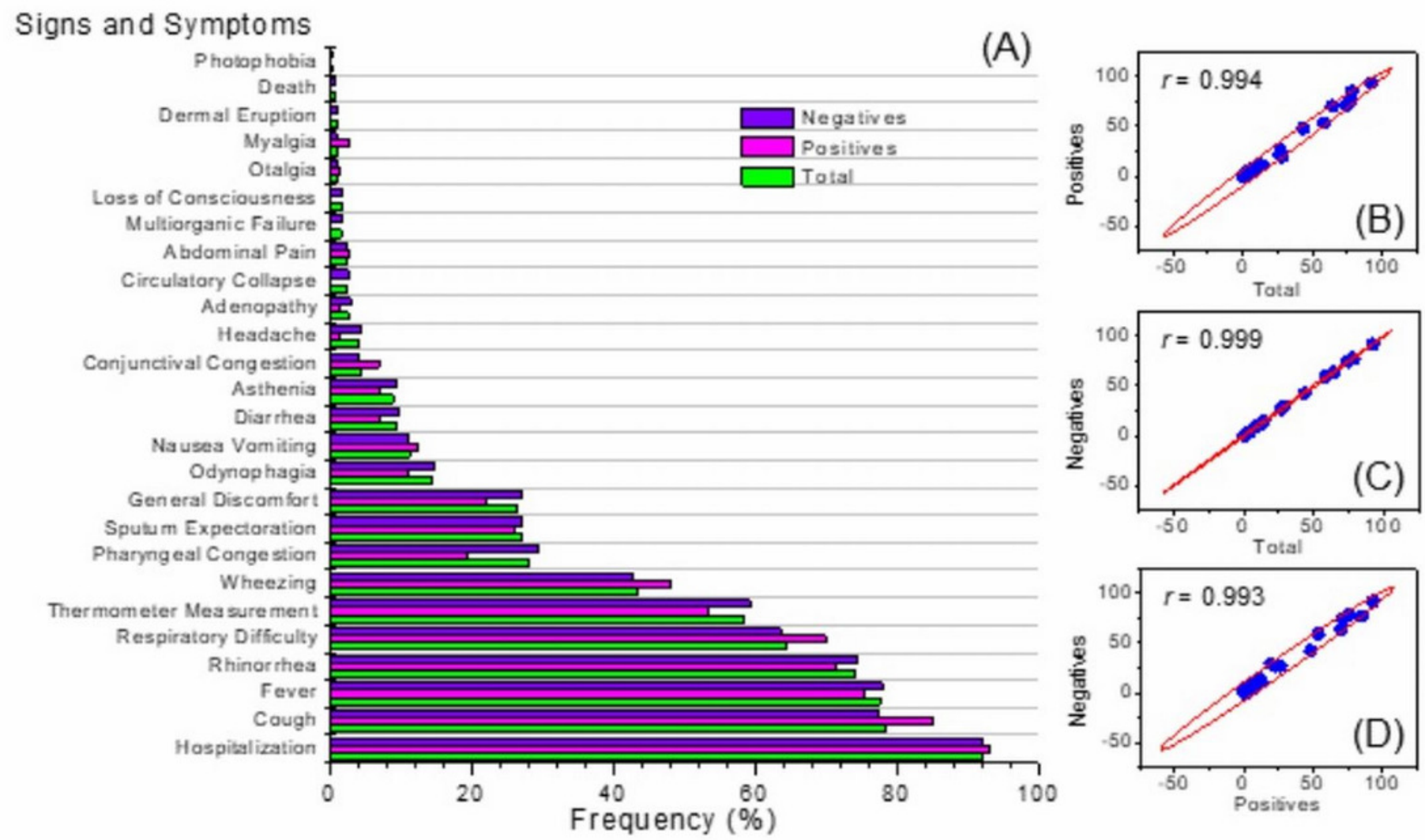


\section{Figure 3}

Figure 3. Monthly distribution of cases. The gray box indicates the months of greatest incidence. Inset, seasonal distribution.

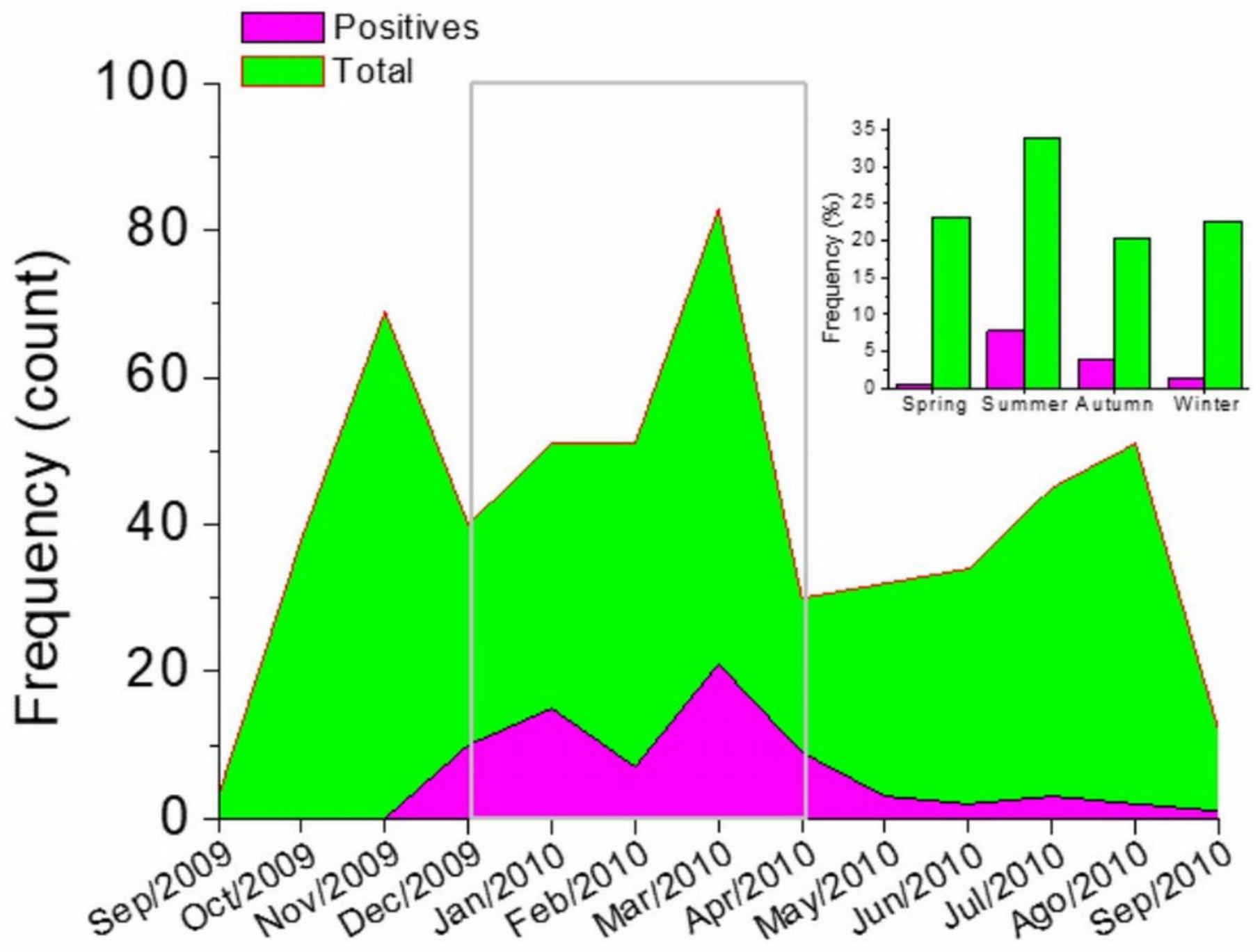

